\title{
A novel insight into the fabrication of Polyhydroxyalkanoates from actinobacteria Streptomyces toxytricini D2: screening, optimization, and biopolymer characterization
}

Mathiyazhagan Narayanan

Dr MGR College of Pharmacy

Suresh Kumarasamy

Dr MGR College of Pharmacy

Gajendiran Kandasamy

Adhiyamaan College of Engineering

Sabariswaran Kandasamy

Jiangsu University

Bhuvanendran Narayanamoorthy

Jiangsu University

Arivalagan Arivalagan Pugazhendhi ( $\sim$ pugal.smile@gmail.com )

Ton Duc Thang University

\section{Research Article}

Keywords: Polluted soil, S. toxytricini D2, PHAs, TEM, FTIR, NMR, Optimization

Posted Date: September 29th, 2021

DOI: https://doi.org/10.21203/rs.3.rs-924055/v1

License: (c) (1) This work is licensed under a Creative Commons Attribution 4.0 International License.

Read Full License

Version of Record: A version of this preprint was published at Journal of Polymers and the Environment on November 23rd, 2021. See the published version at https://doi.org/10.1007/s10924-021-02336-7. 


\section{Abstract}

The objective of this study was to find a biopolymer producing potential actinobacteria candidate from polluted soil. A biopolymer fabricating Streptomyces toxytricini D2 was isolated and characterized by $16 \mathrm{~S}$ rRNA sequencing. The $S$. toxytricini $\mathrm{D} 2$ produced polymeric granules were categorized by FTIR, $1 \mathrm{H}$ NMR, and 13C NMR analyses and confirmed that the produced granules were Polyhydroxyalkanoates (PHAs). The S. toxytricini D2 has the competence to fabricate $86.56 \%$ of PHAs $\left(23.64 \mathrm{~g} \mathrm{~L}^{-1}\right.$ of PHAs from $27.31 \mathrm{~g}$ $\mathrm{L}^{-1}$ of biomass) under the optimized growth conditions: $8 \%$ of tapioca molasses, $4 \%$ of $\left(\mathrm{NH}_{4}\right)_{2} \mathrm{SO}_{4}, 8 \%$ of inoculum, $\mathrm{pH} 6.5,30^{\circ} \mathrm{C}$ and $72 \mathrm{~h}$ of incubation. These results concluded that this is the novel report about the $S$. toxytricini D2 as could be used as an efficient candidate for the mass production of PHAs polymer under optimized conditions with low-cost carbon source and in a short duration of the production process.

\section{Introduction}

The wide applications such as building materials, equipment's, packaging, etc. nature of plastic, the requirements are raising every day in the entire word (Lai et al., 2020; Mohapatra et al., 2017). The continuous usage of non-renewable petroleum-based plastics would be exhausted very soon due to excess utilization and less recycle management technology (Dai et al., 2020; Pérez et al., 2020). Besides that, the frequent usages and unscientific disposal of these traditional polymers creating severe soil and water pollution (Alshehrei, 2019). Furthermore, while during accidental burning, it releasing toxic greenhouse gases into the environment and cause severe air pollution (Mohapatra et al., 2017). The abandoned used plastic materials persist in the environment for several years due to its less or nondegradability in nature (Huang et al., 2020; Xiong et al., 2020). However, the instant complete avoidance of these traditional plastics are not possible without finding an eco-friendly alternate material for traditional plastic (He et al., 2018). Fortunately, nature has to provide an excellent renewable sources through microbes and plants (Pérez et al., 2020). Among these, the microbes, especially the bacteria, is one of a preferable source for eco-friendly biodegradable plastic production (Girão et al., 2019; Zhang et al., 2020). The bacterial based biopolymer producing bacteria isolation and biopolymer production receiving more attention among researchers due to its multiple application as similar to traditional plastics and with fast biodegradable in nature (Banu et al., 2019). The significant variation among conventional polymers with biopolymers is possibilities of microbial degradation after utilization of them. Since the most percentage of biopolymers are made up of carbon and nitrogen, which could act as a nutrient for microbial growth and leads to reduce as a carbon dioxide and water through microbial enzyme activity (Zikmanis et al., 2020). Among various bacterial based polymers, the polyhydroxyalkanoates (PHAs) is a most preferable polymer as it could be synthesized by several numbers of bacteria as an energy backup nutrient components and protect the bacterial cell from adverse environmental stress conditions and limited quantity of essential elements such as nitrogen and phosphorous (Koutník et al., 2020). Numerous bacterial species such as Bacillus sp., Alcaligenes eutrophus, A. latus, Protomonas extorquens, P. oleovorans, Azotobacter vinelandii, Escherichia coli, etc. 
had been reported as suitable candidates for the fabrication of biopolymer (PHA) (Kucera et al., 2018; Pérez et al., 2020). The poly(3-hydroxybutyrate) and poly(3-hydroxybutyrate-3-hydroxyvalerate (PHBV) are a major part of PHA (Banu et al., 2019). Most of the bacterial species accumulating these PHA molecules in the cell cytoplasm (Shanmugam \& Abirami, 2019). These mobile, amorphous, and liquid granules present in the cytoplasm region of actinobacteria and might are support the growth of bacteria under environmental stress conditions biopolymers allowing microbial survival under stress conditions (Girão et al., 2019). However, the successful replacement of traditional oil-based polymers by biopolymer is limited due to the cost of mass production (Zikmanis et al., 2020). Hence to sort out these issues, finding a cheap raw material (carbon and nitrogen sources) utilizing and biopolymer producing bacterial candidate is timely needed. Therefore in this study, apart from common bacterial species, the actinobacterial species (S. toxytricini D2) isolated from industrial effluents polluted site has been investigated to assess their PHA producing competence and it could be foremost report. Very few number of actinobacterial species such as Kineosphaera limosa, Rhodococcus sp., Nocardia sp., etc. are found as fine PHA accumulating actinobacteria (Singh Saharan et al., 2014). The PHAs produced intracellularly and stored as carbon and energy reservoir by several bacteria. The PHA accumulated in the actinobacteria is located in the cell cytoplasm, mobile, amorphous, and this liquid granules are allowing the actinobacteria survival under abiotic stress conditions including nutritional factors and the presence of excess carbon source (Sathiyanarayanan et al., 2013). Based on the aforementioned perspectives, this research was designed to isolate the most active PHA producing actinobacteria species from polluted soil and characterized the PHA and optimized the growth parameters.

\section{Materials And Methods}

\subsection{Collection and processing of soil sample}

The Hosur SIPCOT region has been chosen for this study, since the bacteria which exists in the contaminated soil, for the successful survival they should possess the competence to produce the biopolymeres like molecules (Zikmanis et al., 2020). With this presumption, about $10 \mathrm{~g}$ of polluted soil from four different SIPCOT region was collected from 5-10 cm depth individually in ethanol sterilized glass container. The sample collected containers were immediately transferred to the laboratory and performed the studies continuously.

\subsection{Enumeration of Actinobacteria culture}

The enumeration of indigenous actinobacteria from polluted soil sample was achieved by standard serial dilution process. About $0.1 \mathrm{ml}$ of $10^{-5}$ dilution from each (four) samples were inoculated on actinobacteria isolating selective media (YIM 7 HV medium) by spread plate method (Girão et al., 2019). The YIM 7 HV medium (pH 7.2) contain $0.5 \mathrm{~g}$ of Disodium hydrogen phosphate, $1.0 \mathrm{~g}$ of Humic acid, 1.7 $\mathrm{g}$ of potassium chloride, $0.05 \mathrm{~g}$ of Magnesium sulfate, $0.01 \mathrm{~g}$ of Ferrous sulfate heptahydrate, $1 \mathrm{~g}$ of Calcium dichloride $0.5 \mathrm{mg}$ of each B-vitamins, $20 \mathrm{~g}$ of agar for $1000 \mathrm{ml}$ distilled water. The inoculated plates were incubated at $30^{\circ} \mathrm{C}$ for $48 \mathrm{~h}$ with proper labelling. 


\subsection{Screening of biopolymer producing actinobacteria \\ 2.3.1 Primary screening}

In the initial screening process total of 17 active cultivable actinobacteria isolates were isolated from YIM $7 \mathrm{HV}$ medium. The biopolymer producing potential of these isolates was analysed (Rendón-Villalobos et al., 2016). Briefly, the pure form of these 17 well grown colonies were individually treated (poured over the grown colonies) with $2.5 \mathrm{ml}$ of $0.05 \%$ of Sudan Black B stain and kept undisturbed for 30 min at room temperature and then rinsed with $60 \%$ ethyl alcohol. The Sudan Black B stained plates were incubated at room temperature for $35 \mathrm{~min}$ and observed the formation as black greenish-blue color, deliberated as positive for PHAs biopolymer.

\subsubsection{Secondary screening}

The PHA primary screening results revealed that among 17 predominant isolates, the isolate $\mathrm{H} 09$ only indicated as a positive for PHA producer. The PHA producing potential of this isolate was identified by exposed to the PHA selective media ( $0.25 \mathrm{~g}$ of potassium dideuterium phosphate, $2.5 \mathrm{~g}$ of di-sodium hydrogen phosphate dehydrate, $10 \mathrm{~g}$ of mannitol, $2 \mathrm{~g}$ of sodium chloride, $0.1 \mathrm{~g}$ of magnesium sulphate, $10 \mathrm{~g}$ of sodium pyruvate, $1 \mathrm{~g}$ of peptone, $0.12 \mathrm{~g}$ of bromothymol blue, and $2 \mathrm{~g}$ of agar) test. A loop full of test isolate ( $\mathrm{H09}$ ) was inoculated on this PHA selective media containing plate and incubated at $30^{\circ} \mathrm{C}$ for $48 \mathrm{~h}$. The development of deep bluish-black colonies was identified as PHA positive isolate (Krishnan et al., 2017).

\subsubsection{Tertiary screening by morphological analysis}

The Transmission Electron Microscope (TEM) (TEM- Talos F200i Thermo Fisher, Mumbai, India) was used to finalize the PHA producing potential of test isolate $\mathrm{HO9}$ by following the standard protocol (Nwinyi \& Owolabi, 2019). Briefly, about $2.5 \mathrm{~mL}$ of test $(\mathrm{H} 09)$ isolate $\left(1 \times 10^{2}\right.$ cells $\left.\mathrm{mL}^{-1}\right)$ at exponential phase was fixed with glutaraldehyde (4\%), subsequently with osmium tetroxide (1\%) and desiccated with $80-100 \%$ of acetone by consecutive treatment. The dried and fixed cells were submerged in epoxy resin and kept at sample boat, and the resin was polymerized at $60^{\circ} \mathrm{C}$ for $24 \mathrm{~h}$. Sub sequentially, the resincoated fixed cells were stained with uranyl acetate $(22 \mathrm{~min})$ and lead citrate $(5 \mathrm{~min})$ and observed under TEM.

\subsection{Molecular characterization of $\mathrm{H} 09$}

The results attained from the screening studies stated that the only one isolate (H09) out 17 has the potential to produce PHA. The basic cultural and morphological characteristics were studied, and the test culture was suspected as might belongs to actinobacteria group. Hence, the 16s rRNA sequencing was achieved to recognize the genus and species of test isolate (H09). Briefly, the standard RNA extraction kit from SRL Chemicals, Pvt. Ltd, Mumbai, India has been used to extract the RNA and amplified with standard universal primer (8F (5'-AGAGTTTGATCCTGGCTCAG-3'). The PCR amplification conditions were optimized as: denaturation: $95^{\circ} \mathrm{C}(2 \mathrm{~min})$, annealing: $55^{\circ} \mathrm{C}(30 \mathrm{~s})$, and extension was at $72{ }^{\circ} \mathrm{C}(10 \mathrm{~min})$ 
with 30 cycles. The amplified PCR component was decontaminated by the PCR product purification kit (SRL Chemicals, Pvt. Ltd, Mumbai, India) and sequencing system (518F/800R) was used for sequencing the purified PCR product (Nwinyi \& Owolabi, 2019). The aligned sequences were identified at the National Center for Biotechnology Knowledge (https:/blast.ncbi.nlm.nih.gov/ Blast) in regions of local similarity with Genbank database by nucleotide BLAST. Based on similarly scores with registered species, the isolated species were described by Neighbour-joining method max sequence difference of 0.75 distance using BLAST. Furthermore, the sequence was registered at NCBI and received accession numbers as MT228958.1 (Kumar et al., 2020).

The MFE secondary structures of Streptomyces toxytricini D2 was predicted using the available online RNAWebSuite/RNAfold bioinformatics tools. The following link was used http://rna.tbi.univie.ac.at/cgibin/RNAWebSuite/RNAfold.cgi (Bhattacharjee et al., 2012). To assess the possibilities of genetic modification in this attained $S$. toxytricini $\mathrm{D} 2$ was studied by bioinformatics tool. The restriction sites in $16 S$ rRNA of $S$. toxytricini D2 was analysed using NEB cutter programme version 2.0. The following links were used http://nc2.neb.com/NEBcutter2/cutshow.php?name=6e610b1b-MT228957.1 (Hajiaghayi et al., 2012).

\subsection{Extraction of PHA from Streptomyces toxytricini D2}

The PHA fabricating test isolate was found as Streptomyces toxytricini D2 by $16 \mathrm{~S}$ rRNA sequencing. For the characterization of PHA molecule synthesised by S. toxytricini D2 was extracted (Alarfaj et al., 2015). Concisely, the biomass of $S$. toxytricini D2 (earlier or middle stationary phase) from YIM 7 HV broth medium was extracted by spun at $10000 \mathrm{rpm}$ for $8 \mathrm{~min}$. Then pellet was treated $1 \mathrm{~min}$ with acetone and ethanol (1:1 ratio) to break the cell wall and to extract the PHAsgranules from S. toxytricini D2 and subsequently centrifuged at 10000 for 3 min and discarded the supernatant. About $1 \mathrm{~mL}$ of $4 \% \mathrm{NaOCl}$ was added to dissolve the pellet and kept undisturbed for $30 \mathrm{~min}$ at room temperature and centrifuged at $10000 \mathrm{rpm}$ for $5 \mathrm{~min}$. around 2:1 ratio of acetone and ethanol was used to wash the pellet. Then the polymers containing pellet was dissolved with sufficient quantity of chloroform and filtered by filter paper (Whatman No. 1). The polymers containing filtrate was treated with $5 \mathrm{~mL}$ of concentrated sulfuric acid to reduce the polymeric granules into crotonic acid. The optical absorbance value of this sample was read at $240 \mathrm{~nm}$ using UV-Vis spectrophotometer (UV/Vis/NIR-LAMBDA 1050+, PerkinElmer, USA), and with various concentration of commercial PHA (SRL, Chemicals Pvt. Ltd., Mumbai, India) molecule was used as a reference.

\subsection{Characterization of PHA extracted from S. toxytricini D2 2.6.1. Fourier Transform Infrared Spectroscopy study}

The polymeric granules produced and extracted from $S$. toxytricini D2 was subjected to FTIR analysis (Alarfaj et al., 2015). Briefly, a portion of crude PHA (1 mg) extracted from procedure above was dissolved with chloroform $(5 \mathrm{~mL})$ and mixed gently for few minutes. About few drops of the sample was smeared on FTIR KBr disk (PerkinElmer, spectrum $3^{\text {TM }}$ Tri-Range FTIR). Then the spectra of solvent evaporated PHA 
extract and were read at decent resolution $\left(4 \mathrm{~cm}^{-1}\right)$ with vacuum pressure of $400-4000 \mathrm{~cm}^{-1}$ by using IR double beam spectrophotometer.

\subsection{2. ${ }^{1} \mathrm{H}$ NMR analysis}

The monomers $(1 \mathrm{H})$ contents of PHA molecules produced by $S$. toxytricini D2 was characterized using ${ }^{1} \mathrm{H}$-NMR analysed (Alarfaj et al., 2015). About $10 \mathrm{mg}$ of crude PHA granules were dissolved with $1 \mathrm{~mL}$ of chloroform, and Tetramethyl saline was utilized as an internal reference. The spectra of liquefied PHA molecules were recorded in DMSO on Bruker ACF300 spectrophotometer at $300.53 \mathrm{MHz}$ frequency with the resolution of $>0.1 \mathrm{deg}$ and $>0.1 \mathrm{~Hz}$ respectively.

\subsection{3. ${ }^{13} \mathrm{C}$ NMR analysis}

The carbon skeleton of $20 \mathrm{mg}$ of concentrated PHA (CDCl3 dissolved) molecules extracted from $S$. toxytricini $\mathrm{D} 2$ was recorded at $30^{\circ} \mathrm{C}$ by ${ }^{13} \mathrm{C}$ NMR (Baran et al., 2018) using a $500 \mathrm{MHz}$ NMR spectrometer (Bruker ACF300 spectrophotometer: has ${ }^{1} \mathrm{H}$ and ${ }^{13} \mathrm{C}$ dual probe) with the MAS frequency of $170 \mathrm{MHz}$ and $10 \mathrm{kHz}$ correspondingly.

\subsection{Growth parameters optimization for PHA synthesise}

To assess the PHA secreting extent potential of $S$. toxytricini D2, the basic growth parameters and find low cost nutritional factors were studied as one-factor-at-a-time mode (Narayanan et al., 2020). The parameters such as various concentrations $(2,4,6,8$, and $10 \%)$ of different carbon (w / v) sources such as pre-treated tapioca molasses, sugarcane molasses, and pulverized rice bran. The different concentrations $(1,2,3,4$, and $5 \%)$ of various nitrogen sources such as $\left(\mathrm{NH}_{4}\right)_{2} \mathrm{SO}_{4}, \mathrm{NH}_{4} \mathrm{NO}_{3}$, and yeast extract were added in minimal medium (contain: $0.5 \mathrm{~g}$ of $\mathrm{MgSO}_{4} 7 \mathrm{H}_{2} \mathrm{O}, 0.5 \mathrm{~g}$ of NaCl, $1 \mathrm{~g} \mathrm{~L}^{-1}$ of $\left.\mathrm{K}_{2} \mathrm{HPO}_{4}\right)$. Various percentages $(2,6,8,10$, and $12 \%)$ of inoculum of $S$. toxytricini $\mathrm{D} 2\left(1 \times 10^{6} \mathrm{CFU} \mathrm{mL}\right)$ were studied. The various degrees of temperature $\left(25,30,35\right.$, and $\left.40^{\circ} \mathrm{C}\right)$, different $\mathrm{pH}(6.5,7.5,8.5$, and $9.5)$ and various incubation time $(24,48,72$, and $96 \mathrm{~h})$ were evaluated. The each parameters were achieved with triplicates to attain results accuracy and reproducibility. The bacteria inoculated with parameters mentioned above containing media were incubated on a shaker incubator with $150 \mathrm{rpm}$ for up to $96 \mathrm{~h}$. The amount of PHA produced (extracted by previous method), and growth of S. toxytricini D2 from each parameter was studied at $240 \mathrm{~nm}$ and $600 \mathrm{~nm}$ respectively by UV-Vis spectrophotometer on day interval basis (Getachew \& Woldesenbet, 2016).

\subsection{Growth kinetics and production of PHA under optimized conditions}

The optimized growth conditions for the maximum PHA production by S. toxytricini D2 were $8 \%$ of tapioca molasses, and $4 \%$ of $\mathrm{NH}_{4} \mathrm{NO}_{3}$ were served as suitable carbon and nitrogen sources respectively. Furthermore, $8 \%$ of inoculum, $30^{\circ} \mathrm{C}, \mathrm{pH} 6.5$, and $72 \mathrm{~h}$ of incubation were optimized as suitable growth conditions for PHA fabrication by $S$. toxytricini D2. The maximum PHA producing potential of $S$. toxytricini D2 was studied by inoculating $6 \%$ of $S$. toxytricini D2 $\left(1 \times 10^{6} \mathrm{CFU} \mathrm{mL}\right)$ on minimal broth 
medium compiled with optimized parameters ( $8 \%$ of tapioca molasses, $4 \%$ of $\mathrm{NH}_{4} \mathrm{NO}_{3}, 30{ }^{\circ} \mathrm{C}, \mathrm{pH} 6.5$ ) and incubated in a shaker incubator for $72 \mathrm{~h}$ with $120 \mathrm{rpm}$. The growth kinetics and PHA production were recorded by method as mentioned earlier (Krishnan et al., 2017).

\subsection{Statistical analysis}

All the experiments were performed in triplicate mode to achieve accuracy and reproducible results. Furthermore, the mean, standard error, and one- way ANOVA were performed using SPSS. Software version 13.

\section{Results And Discussion \\ 3.1. Brief profile of soil sample collected site}

The soil samples collected sites have been polluted by various industrial activities, since it is an industrial area. Hence the bacteria that survive in this abiotic stress environment as a lifesaving mechanisms the bacteria could secrete different kinds' high molecular weight molecules such as polysaccharides, polyamides, polyesters, and polyphosphates. These polymeric components can act as protective capsular layers for bacteria that survive under abiotic stress conditions (Moradali \& Rehm, 2020). The synthesis and mobilization of PHA in bacteria have been directly related to environmental stress and fit for survival under abiotic stress (Niether et al., 2020). These metabolically adapted bacterial strains could produce fine quality and quantity of biopolymers.

\subsection{Enumeration of biopolymer producing predominant isolate}

About 17 bacterial isolates have been screened from a polluted soil sample collected from an industrial site. Different morphological characteristics bacteria were observed, nevertheless in the initial Sudan Black B stain screening study stated that only one bacterial strain was showed dark blueish black color colonies and this was deliberated as positive for PHA producer (Mostafa et al., 2020). The Sudan black B can stain the lipid or lipid-associated polysaccharide material (polymeric) and produced deep blue-black color. On secondary screening in PHA selective media, deep bluish-black colonies of H09 was observed in the well-grown plate.

As a final confirmation, the TEM analysis was achieved to identify the PHA producing potential of isolate H09. The TEM images of test isolate $\mathrm{H} 09$ were showed that the presence of polymeric granules (PHA) located at the close region of the cytoplasmic membrane (Fig. 1). Most of the produced PHA granules were uniformly oval and elongated in shape with clear boundary line of each granule were seen in the cytoplasmic region of test isolate H09. Similarly, halophilic archaea isolated from polluted soil produces spherical, ovoid, and elongated shaped granules (Danis et al., 2015). This multi-shaped granules might cause little complications in the purification process. Fortunately, the granules produced by test isolate 
H09 showed identical in shape that could be considered as more advantage of this test isolate for mass production with fine quality polymeric substances.

\subsection{Genomic identification of test isolate}

The PHA was producing test isolate H09 was genotypically characterized using 16S rRNA analysis. The amplification characteristics of the 16S rRNA gene of isolate H09 were carried out by PCR and sequencing systems. The 1400 bp 16S rRNA genes sequence of isolate H09 was a blast and registered in GenBank http://www.ncbi.nlm.nih.gov/genbank and acquired the accession number from NCBI as Streptomyces toxytricini D2 (MT228958.1). The partial sequence of the S. toxytricini D2 (MT228958.1) was compared with sequences of already existing genera of actinomycetes from NCBI database to determine the phylogenetic relatedness clustered together as one clade segments corresponding to an evolutionary distance of 0.002 and 0.009 as shown with bars by using Neighbour-joining method (Fig. 2). It was revealed that the sequence of the isolate $S$. toxytricini D2 found 99\% similarity with the existing species of S. toxytricini strain HBUM174624 (Fig. 2). The results were directly compared with the previous findings (Charousová et al., 2018; Salgaonkar \& Bragança, 2017). They isolated commercially valuable Streptomyces sp. from polluted soil and characterized through 16S rRNA sequencing and compared by phylogenetic analysis. The Minimum Free Energy (MFE) secondary structure of the 16S rRNA gene of $S$. toxytricini D2 (MT228958.1) showed 27 stems in their MFE structure (Fig. 3). However, S. toxytricini D2 has GC-59\% and AT-41\% (Fig. 3). These observations also agree with the results reported by researchers on Streptomyces sp. isolated from soil sample (Heinsch et al., 2019). The S. toxytricini D2 is a mesophilic soil bacteria and previously reported as a suitable candidate for commercially valuable enzyme production (Kumar et al., 2020). The genetic modification in S. toxytricini D2 is possible due to appropriate restriction sites and its fine GC content could balance the stability to broad growth conditions (Bhagowati et al., 2015). Thus, this genomic trait of S. toxytricini D2 could support the biopolymer commercial production.

\subsection{Categorisation of PHA produced by S. toxytricini D2}

The polymeric extracted from $S$. toxytricini D2 was successfully removed and confirmed as PHA by compared with reference PHA (commercially available) molecule by UV-Vis spectrophotometer with absorbance in the range of 200 to $360 \mathrm{~nm}$ (Sathiyanarayanan et al., 2013). The highest absorbance peak for PHA extract was recorded at $240 \mathrm{~nm}$ (OD value: 2.46) and it was almost identical to commercial PHA (OD value: 2.40) and it confirmed that the extracted polymer was PHA molecule (Fig. 4). Similarly, the polymeric granules are also removed from the Bacillus subtilis NCDC0671 and confirmed that molecule as PHA through UV-Vis spectrophotometer analysis (Umesh et al., 2018).

\subsubsection{FT-IR}

The figure. 5 displays the FTIR spectrum of the Polyhydroxyalkanoates as extracted from S. toxytricini D2. The absorption band appeared at around $3500 \mathrm{~cm}^{-1}$ associated with the free-hydroxyl group's stretching frequency in the polymer chain (Alarfaj et al., 2015). The multiple peaks were observed 
between 2800 and $3100 \mathrm{~cm}^{-1}$ corresponding to the symmetric and asymmetric stretching vibrations of $\mathrm{CH}_{3}$ and $-\mathrm{CH}_{2}-\mathrm{CH}_{3}$ alkane groups. Furthermore, the low intensity of $--\mathrm{CH}_{3}$ peak attributes the crystallisation process's conformational disorder (Biradar et al., 2018). Interestingly, the absorption band of carbonyl functional group was observed as the doublet of ketone group $(C=0)$ at nearly $1742 \mathrm{~cm}^{-1}$ and amide group $(\mathrm{N}-\mathrm{C}=0)$ at $1660 \mathrm{~cm}^{-1}$, corroborates the stretching vibrations of carbonyl ester and intracellular amide of microbes respectively (López-Cuellar et al., 2011; Mostafa et al., 2020). The terminal methyl group $\left(-\mathrm{CH}_{3}\right)$ was confirmed from the intense peak observed at $1379 \mathrm{~cm}^{-1}$, and the cluster of absorption peaks appeared at below $1200 \mathrm{~cm}^{-1}$ might be associated with the stretching frequency of - C-O-C-, -C-O and - C-C- functional groups (Getachew \& Woldesenbet, 2016). The FTIR spectrum's designated absorption peaks (Fig. 5) reveals that the formation of PHA polymer in amorphous phase with a trace amount of impurities from the starting materials and well correlated with the reported literature (Bhatt et al., 2008; López-Cuellar et al., 2011).

\subsection{2. ${ }^{1} \mathrm{H}$ NMR and ${ }^{13} \mathrm{C}$ NMR analysis}

The structural specifics of $S$. toxytricini $\mathrm{D} 2$ produced PHAs were studied by ${ }^{1} \mathrm{H}$ NMR and ${ }^{13} \mathrm{C}$ NMR analyses. The figure. 6 shows the ${ }^{1} \mathrm{H}$ NMR spectrum of the PHAs produced by S. toxytricini. The resonance signal observed at $5.25 \mathrm{ppm}$ was due to methylene protons adjacent to carboxyl groups of HB (Linton et al., 2012). Whereas the multiplet resonance of protons of methylene and methane of a-carbon were observed at $2.5 \mathrm{ppm}$. Peaks at 1.45-1.52 ppm were observed concerning the methylene protons adjacent to the $\beta$-carbon of the saturated side chain (Bhuwal et al., 2013; Singh et al., 2011). The predominant peak observed at $1.23 \mathrm{ppm}$ is ascertained to the presence of methyl protons of the side chain.

The figure. 7 shows the ${ }^{13} \mathrm{C}$ NMR spectrum of PHAs produced by S. toxytricini D2. The carbon resonance peak observed at $22.72 \mathrm{ppm}$ was due to the presence of methyl carbon. The peaks observed from 43.09 to $45.2 \mathrm{ppm}$ were due to the saturated side chain's methylene carbon. Further peaks were observed at $138.5 \mathrm{ppm}$ for methylene carbon attached to a carboxylic acid group. At $173.10 \mathrm{ppm}$ carboxyl carbon peak was observed (Sabarinathan et al., 2018; Yalpani et al., 1991). Thus the results of ${ }^{1} \mathrm{H}$ and ${ }^{13} \mathrm{C}$ NMR spectra indicated that the intracellular molecules produced by $S$. toxytricini D2 were mostly identical with the PHAs.

\subsection{The growth parameters optimization for PHA production by $S$. toxytricini D2}

The favorable growth conditions are the most significant factor in attaining the expression of the maximum potential of all organisms (Charousová et al., 2018). Similarly, the bacteria also required the most suitable growth conditions for more human and environmental welfare products such as PHA (Krishnan et al., 2017). In this study, the optimal growth requirements such as the various concentration of various low-cost carbons sources (tapioca molasses, sugarcane molasses, and pulverized rice bran), nitrogen sources $\left(\left(\mathrm{NH}_{4}\right)_{2} \mathrm{SO}_{4}, \mathrm{NH}_{4} \mathrm{NO}_{3}\right.$, and yeast extract), different percentage of inoculum, temperature, 
$\mathrm{pH}$, and different incubation time (one factor at one time) and triplicates were performed for each parameter analysis.

\subsubsection{Suitable carbon and nitrogen sources}

For the effective and quality microbial production process, generally, the microbes require carbon and nitrogen sources as most significant factor and it determines the quantity and quality of microbial products such as biopolymers (PHA) (Krishnan et al., 2017). The carbon and nitrogen sources are the most significant microbial product quality and quantity determining factors (Mohapatra et al., 2017). The S. toxytricini D2 effectively utilized and produced PHA (86.65\%) at $8 \%$ concentration of tapioca molasses as $17.34 \mathrm{~g} \mathrm{~L}^{-1}$ of PHA from $20.01 \mathrm{~g} \mathrm{~L}^{-1}$ of cell biomass. It was statistically significant $(p>0.03)$ to other concentration and carbon source. The pulverized rice bran, and sugarcane molasses were acted as a fine carbon source for S. toxytricini D2 and produced $80.18 \%$ and $69.81 \%$ of PHA at $10 \%$ concentration of both carbon sources, respectively (Fig. 8 a to $8 \mathrm{c}$ ). At $10 \%$ concentration, these acquired value were statistically significant at $p>0.05$ than other concentrations ( 2 to $8 \%$ ) of pulverized rice bran and sugarcane molasses. About $4 \%$ of $\left(\mathrm{NH}_{4}\right)_{2} \mathrm{SO}_{4}$ was served as a most suitable nitrogen source for $\mathrm{PHA}$ (66.02\%) production in S. toxytricini D2 as produced $8.2 \mathrm{~g} \mathrm{~L}^{-1}$ of PHA from $12.42 \mathrm{~g} \mathrm{~L}^{-1}$ of cell biomass, and it was statistically significant $(p>0.03)$ to other concentration and nitrogen source (Fig. $8 \mathrm{~d}$ to $8 \mathrm{f}$ ). The S. toxytricini D2 produced 51.47 and $61.85 \%$ of PHA from $4 \%$ of $\mathrm{NH}_{4} \mathrm{NO}_{3}$ and yeast extract correspondingly. The statistical significance of these values among the remaining concentrations were $p$ $>0.05$. These results indicate that even though the carbon and nitrogen sources are essential factor, when their concentrations increase, the bacteria could not utilize them all. Furthermore, the presence of excess concentration might reduce cell viability and activity (Pérez et al., 2020). Thus the sufficient quantity of suitable nitrogen and carbon sources could enhance bacterial metabolic activity and growth. It leads to a reasonable quantity of bacterial products (PHA) with fine quality (Rendón-Villalobos et al., 2016). Besides that, the carbon and nitrogen-based substrate determine the type of polymeric component (PHAs and PHBs), since the quantity of carbon atoms exist in the biopolymers are typed into two as 3-5 carbon atoms based PHAs (Short Chain Length PHAs: SCL PHAs) and 6-14 carbon atoms based PHAs (medium-chain length: MCL PHAs), due to the activity of substrate specific PHA synthases that can recognize 3-hydroxyalkanoic acid with assured range of carbon length (Shanmugam \& Abirami, 2019). The MCL PHAs possess more elasticity and low melting temperature with least degree of crystallinity in nature (Zikmanis et al., 2020). The SCL PHAs are termed as polyhydroxybutyrate. It has a high degree of crystallinity $(>50 \%)$ with thermoplastic in nature (high melting temperature: $180^{\circ} \mathrm{C}$ ). Some other low-cost materials also previously reported such palm (Gabr, 2018; Khiyami et al., 2011) had been recorded as suitable carbon source for bacterial (Bacillus sp.) based biopolymer (PHA and PHB) production (58\%). The maximum volume of PHAs could be synthesized under the limited dosage of nitrogen contents (Patel et al., 2017). It was correlated with this study's findings since more quantity of PHAs produced at $4 \%$ concentration of $\left(\mathrm{NH}_{4}\right)_{2} \mathrm{SO}_{4}$ than $5 \%$. The limited nitrogen sources with readymade form could improve the biopolymer yield (Kourmentza et al., 2017).

\subsubsection{Percentage of inoculum}


The percentage of inoculum applied on the microbiological fermentation process received more attention as it determine the volume of yield and time duration of production process (Charousová et al., 2018). In this study, about $8 \%$ of inoculum of $S$. toxytricini D2 produced a reasonable quantity (66.7\%) of PHAs (12.34 $\mathrm{g} \mathrm{L}^{-1}$ of PHAs from $18.5 \mathrm{~g} \mathrm{~L}^{-1}$ of cell biomass) in a short duration of incubation than other dosages (Fig. 8g). It was statistically significant $(p>0.03)$ to other concentration. It followed by $10 \%$ of inoculum produced $62.74 \%$ of PHAs (Fig. $8 \mathrm{~g}$ ). The high dosage of inoculum might minimize the lag phase of the bacterium and enhance it to reach the log phase. There the PHAs production gets initiated; thus the short duration of the cell biomass could produce more volume of PHAs (Bhatt et al., 2008). Nevertheless, less PHAs yield was noted in $10 \%$ inoculum since at the inoculum concentration the cell might utilize more volume of nutrients during the lag phase itself (batch typed fermentation). At the same time, it reached to the log phase it faces nutrient depletion leads to less production (López-Cuellar et al., 2011). Similarly, the low PHAs yield was recorded at a low concentration of inoculum; it could be lag phase might take some more time to reach the log phase with average cell biomass and it leads to low PHAs yield (Mostafa et al., 2020). The dosage of inoculum for each bacteria for the production (fermentation) process should differ (Alshehrei, 2019). Accordingly, about $12.5 \%$ of inoculum of Bacillus sp. was found as an optimized dosage for biopolymer (PHAs and PHBs) production (Getachew \& Woldesenbet, 2016).

\subsubsection{The suitable temperature}

Among the various physical parameters, the temperature plays a most significant role in the active growth of microbes (Girão et al., 2019). It determines the yield of biomass and microbial products since, under the optimized temperature, only the bacteria can continue their metabolic process (Johnson et al., 2010). In this study, the optimal temperature for significant growth and PHAs producing competence of $S$. toxytricini D2 was found as $30^{\circ} \mathrm{C}$. The PHAs yield was observed as $72.95 \%\left(10.36 \mathrm{~g} \mathrm{~L}^{-1}\right.$ of PHAs from $14.2 \mathrm{~g} \mathrm{~L}^{-1}$ of cell biomass) at $30^{\circ} \mathrm{C}$ and followed by $35^{\circ} \mathrm{C}$ (Fig. 8h), and it was statistically significant ( $p>$ $0.03)$ to other temperature. Low PHAs and biomass yield were recorded at $25^{\circ} \mathrm{C}(37.06 \%)$ and $40^{\circ} \mathrm{C}$ (62.74\%). Several researchers have been reported that the optimal temperature for PHAs production through various bacterial species fell within the range of $25-35^{\circ} \mathrm{C}$ (De Grazia et al., 2017). The extreme and low temperatures might reduce the feast phase of bacteria along with swift nutrients uptake rates. Besides that, the $\mathrm{O}_{2}$ transmission is more proficient at average temperatures since the higher volume of dissolved oxygen persists at average temperature $\left(25-35^{\circ} \mathrm{C}\right)$. In mass production and economic aspects, the average temperature for the production process could minimize the cost of production (Chan et al., 2017). Similarly, species of Nacardiopsis and Vibrio have effectively produced biopolymers at $30^{\circ} \mathrm{C}$ (Mahitha \& Madhuri, 2015). The optimal temperature might vary from species to species. According to this, the Bacillus sp. (Alshehrei, 2019), E. aquimaris (Mostafa et al., 2020), S. thermophilus (Kalaivani \& Sukumaran, 2013), and produce a fine quantity of PHAs at $30^{\circ} \mathrm{C}, 35^{\circ} \mathrm{C}$, and $50^{\circ} \mathrm{C}$ respectively. This temperature differentiation might be related to the temperature of bacteria isolated sites, since the enzymatic and metabolic activity could be significant (Pérez et al., 2020).

\subsubsection{Optimal pH}

Page $11 / 25$ 
The $\mathrm{pH}$ is another most essential factor that regulates the cell metabolic process. Since each enzymatic mechanisms in the cell has been directly related to the $\mathrm{pH}$ of the medium. More microbial products is obtainable under the optimal pH condition (Sasidharan et al., 2015). Accordingly, S. toxytricini D2

produced $67.42 \%$ ( $8.26 \mathrm{~g} \mathrm{~L}^{-1}$ of PHAs from $12.25 \mathrm{~g} \mathrm{~L}^{-1}$ of cell biomass) of PHAs at $\mathrm{pH} 6.5$, and it was statistically significant $(p>0.03)$ to other $\mathrm{pH}$ (Fig. 8i). It might be the PHAs syntheses enzymes of $S$. toxytricini D2 effectively produce and accumulate the PHAs at slightly acidic $\mathrm{pH}$; it chelates the further metabolic process and finally yielded a reasonable volume of PHAs. Similarly, Ralstonia solanacearum produces more biopolymer (PHBs and PHAS) acidic conditions (Macagnan et al., 2017). The optimal pH for bacteria might differed for each for PHA production. Similarly, B. cereus produce high yield of polymeric molecules at pH 7.5 (Macagnan et al., 2017), and for Bacillus sp (F15) pH 7 (Alshehrei, 2019). Moreover, some bacterial species might has the potential to grow under wide range of $\mathrm{pH}$ as acidic to alkaline, for that they developed particular adaptation strategy according to the $\mathrm{pH}$ and balancing the activity of enzymes such as ATP synthase, terminaloxidase (Bhatt et al., 2008), PHAs synthase (Baran et al., 2018) etc. These adaptation strategies permit the bacteria to balance the $\mathrm{pH}$ of cytoplasmic content and regulate optimal cell functioning.

\subsubsection{Suitable incubation time}

To attain the extent beneficial products from microbes, it need to be maintained for sufficient incubation time. In this study, the isolated actinobacteria $S$. toxytricini $\mathrm{D} 2$ produce the maximum yield of PHAs on 72 $\mathrm{h}$ of incubation. The PHAs yield was recorded as $57.58 \%\left(7.21 \mathrm{~g} \mathrm{~L}^{-1}\right.$ of PHAs from $12.52 \mathrm{~g} \mathrm{~L}^{-1}$ of cell biomass), and it was statistically significant $(p>0.03)$ to other incubation time (Fig. 8j). The optimal incubation time for the growth of bacteria might differ from each other. According to this, the Bacillus sp. Ti3 produced $51.6 \%$ of PHAs at $24 \mathrm{~h}$ of incubation time (Bhagowati et al., 2015), Bacillus sp. INT005 (35.30\% in 48 h) (Tajima et al., 2003), Bacillus cereus SPV (38.0\% in 48h) (Valappil et al., 2008), Bacillus mycoides (50\% in $72 \mathrm{~h}$ ) (Soam et al., 2012), Pseudomonas sp, Bacillus sp, and Rhizobium alti, $40 \mathrm{~h}$ (Sathiyanarayanan et al., 2013). The optimized incubation time increasing 1.82 fold of biopolymer production by Bacillus mycoides DFC1 at $72 \mathrm{~h}$ of incubation (Narayanan \& Ramana, 2012).

\subsection{Production of PHA under optimized conditions}

The growth kinetics and extent PHAs producing potential of S. toxytricini D2 were studied with optimized growth conditions such as $8 \%$ of tapioca molasses, $4 \%$ of $\left(\mathrm{NH}_{4}\right)_{2} \mathrm{SO}_{4}, 8 \%$ of inoculum, pH 6.5 , incubated at $30{ }^{\circ} \mathrm{C}$ for $72 \mathrm{~h}$ of incubation period. Under these optimized conditions, the $S$. toxytricini D2 yielded $86.56 \%$ of PHAs as $23.64 \mathrm{~g} \mathrm{~L}^{-1}$ of PHAs from $27.31 \mathrm{~g} \mathrm{~L}^{-1}$ of cell biomass on $72 \mathrm{~h}$ of incubation (Fig. 9). The quantity of PHAs and cell biomass (growth kinetic) were similarly increasing from $24 \mathrm{~h}$ onwards and it was continued up to $72 \mathrm{~h}$ of incubation. Furthermore, the growth of $S$. toxytricini D2 was get decreased from $72 \mathrm{~h}$ on; it indicated that the lag phase of this actinobacteria might take around $24 \mathrm{~h}$, and noticed absence or least amount of PHAs (Fig. 9). The figure. 9 revealed that on after $24 \mathrm{~h}$ of incubation the PHAs was gradually increasing along with cell growth and it declared that these actinobacteria reached the log phase at after $24 \mathrm{~h}$ of incubation and concurrently PHAs get produced on the same time onwards. The growth was reduced on $72 \mathrm{~h}$ of incubation and the PHAs production also halted on the same time of 
incubation, it confirmed that the cell had reached lag stationary and decline phase. The attained yield of PHAs from S. toxytricini D2 was statistically significant with the cell biomass as $p<0.003$.

Moreover, several numbers of bacterial species have been reported about the PHAs production under optimized conditions, the bacteria such as Ralstonia eutropha JMP 134 (50\% of PHAs), Bacillus cereus FA11 (48.43\%), Rhodococcus aetherivorans IAR1 (58.9\%), Haloferax mediterranei (65\%), Halomonas boliviensis LC1 (56\%), H. boliviensis LC1 (88\%), Synechococcus sp. MA19 (55\%) etc. (Maskow \& Babel, 2000; Ni et al., 2010; Singh Saharan et al., 2014). Very few reports are available in the Streptomyces sp. as biopolymer producers such as $S$. griseorubiginosus, $S$. coelicolor, $S$. antibioticus, $S$. venezuelae, $S$. hygroscopicus (Villano et al., 2010), S. aureofaciens, S. griseus, S. parvus, S. albus, etc. (Singh Saharan et al., 2014) all of this have reported as PHB producer. No previous reports are available about the production of PHAs from S. toxytricini D2. Thus this is the foremost study and reported about the PHAs producing potential of $S$. toxytricini $\mathrm{D} 2$ isolated from polluted soil.

\section{Conclusions}

The bacteria enumerated from polluted soil was identified as actinobacteria that have the potential to produce PHAs, and the exact genus and species of this isolate was identified as S. toxytriciniD2 through 16S rRNA analysis. Successive screening studies confirmed the PHAs producing potential of this isolate, significantly the TEM analysis confirmed that the $S$. toxytricini D2 has the potential to produce PHAs. The $\mathrm{FTIR},{ }^{1} \mathrm{H}$ NMR, and ${ }^{13} \mathrm{C}$ NMR analyses were performed for structural confirmation of the polymers produced by $S$. toxytricini D2. The PHAs related signals and peaks were recorded in these technical, structural analyses (FTIR, ${ }^{1} \mathrm{H}$ NMR, and ${ }^{13} \mathrm{C}$ NMR). The suitable growth conditions for $S$. toxytricini D2 were optimized as $8 \%$ of tapioca molasses, $4 \%$ of $\left(\mathrm{NH}_{4}\right)_{2} \mathrm{SO}_{4}, 8 \%$ of inoculum, $\mathrm{pH} 6.5,30^{\circ} \mathrm{C}$ and $72 \mathrm{~h}$ of

incubation. The $S$. toxytricini D2 produced $86.56 \%$ of PHAs (23.64 $27.31 \mathrm{~g} \mathrm{~L}^{-1}$ : PHAs/cell biomass) on 72 $\mathrm{h}$ of incubation. The final results conclude that this is the major study on $S$. toxytricini D2 and reported that this actinobacteria has the excellent potential to produce PHAs molecules by consuming low-cost carbon source and in a short duration of incubation period. Thus, it might be a suitable candidate for making large quantity of PHAs molecules under optimized conditions. The assessment of commercially (PHAs) producing possibilities of this $S$. toxytricini D2 is under progress.

\section{Declarations}

\section{Acknowledgment}

The authors are thankful to the PG and Research Centre in Biotechnology, MGR College, Hosur, Tamil Nadu, India for offering a sophisticated lab facility for successful completion of this study.

\section{References}


1. Alarfaj, A.A., Arshad, M., Sholkamy, E.N., Munusamy, M.A. 2015. Extraction and Characterization of Polyhydroxybutyrates (PHB) from Bacillus thuringiensisKSADL127 Isolated from Mangrove Environments of Saudi Arabia. Brazilian Archives of Biology and Technology, 58(5), 781-788.

2. Alshehrei, F. 2019. Production of Polyhydroxybutyrate (PHB) by Bacteria Isolated from Soil of Saudi Arabia. Journal of Pure and Applied Microbiology, 13(2), 897-904.

3. Banu, J.R., Kumar, M.D., Gunasekaran, M., Kumar, G. 2019. Biopolymer production in bio electrochemical system: Literature survey. Bioresource Technology Reports, 7, 100283.

4. Baran, A., Vrábel, P., Olčák, D., Chodák, I. 2018. Solid state 13C-NMR study of a plasticized PLA/PHB polymer blend. Journal of Applied Polymer Science, 135(21), 46296.

5. Bhagowati, P., Pradhan, S., Dash, H.R., Das, S. 2015. Production, optimization and characterization of polyhydroxybutyrate, a biodegradable plastic by Bacillus spp. Bioscience, Biotechnology, and Biochemistry, 79(9), 1454-1463.

6. Bhatt, R., Shah, D., Patel, K., Trivedi, U. 2008. PHA-rubber blends: Synthesis, characterization and biodegradation. Bioresource Technology, 99(11), 4615-4620.

7. Bhattacharjee, K., Banerjee, S., Joshi, S.R. 2012. Diversity of Streptomyces spp. in Eastern Himalayan region-computational RNomics approach to phylogeny. Bioinformation, 8(12), 548.

8. Bhuwal, A.K., Singh, G., Aggarwal, N.K., Goyal, V., Yadav, A. 2013. Isolation and screening of polyhydroxyalkanoates producing bacteria from pulp, paper, and cardboard industry wastes. International Journal of Biomaterials, 2013.

9. Biradar, G.G., Shivasharana, C., Kaliwal, B.B. 2018. Characterization of polyhydroxybutyrate (PHB) produced by novel bacterium Lysinibacillus sphaericus bbkgbs6 isolated from soil. Journal of Polymers and the Environment, 26(4), 1685-1701.

10. Chan, C.M., Johansson, P., Magnusson, P., Vandi, L.-J., Arcos-Hernandez, M., Halley, P., Laycock, B., Pratt, S., Werker, A. 2017. Mixed culture polyhydroxyalkanoate-rich biomass assessment and quality control using thermogravimetric measurement methods. Polymer Degradation and Stability, 144, 110-120.

11. Charousová, I., Medo, J., Hleba, L., Javoreková, S. 2018. Streptomyces globosus DK15 and Streptomyces ederensis ST13 as new producers of factumycin and tetrangomycin antibiotics. Brazilian Journal of Microbiology, 49(4), 816-822.

12. Dai, X., Lv, J., Yan, G., Chen, C., Guo, S., Fu, P. 2020. Bioremediation of intertidal zones polluted by heavy oil spilling using immobilized laccase-bacteria consortium. Bioresource Technology, 309, 123305 .

13. Danis, O., Ogan, A., Tatlican, P., Attar, A., Cakmakci, E., Mertoglu, B., Birbir, M. 2015. Preparation of poly (3-hydroxybutyrate-co-hydroxyvalerate) films from halophilic archaea and their potential use in drug delivery. Extremophiles, 19(2), 515-524.

14. De Grazia, G., Quadri, L., Majone, M., Morgan-Sagastume, F., Werker, A. 2017. Influence of temperature on mixed microbial culture polyhydroxyalkanoate production while treating a starch industry wastewater. Journal of Environmental Chemical Engineering, 5(5), 5067-5075. 
15. Gabr, G.A. 2018. Isolation and identification of bacterial strains able to biopolymer polyhydroxybutyrate $(\mathrm{Phb})$ production from soil of Al-Kharj probes, Saudi Arabia. Journal of Pharmaceutical Research International, 1-11.

16. Getachew, A., Woldesenbet, F. 2016. Production of biodegradable plastic by polyhydroxybutyrate (PHB) accumulating bacteria using low cost agricultural waste material. BMC Research Notes, 9(1), 1-9.

17. Girão, M., Ribeiro, I., Ribeiro, T., Azevedo, I.C., Pereira, F., Urbatzka, R., Leão, P.N., Carvalho, M.F. 2019. Actinobacteria isolated from Laminaria ochroleuca: A source of new bioactive compounds. Frontiers in Microbiology, 10, 683.

18. Hajiaghayi, M., Condon, A., Hoos, H.H. 2012. Analysis of energy-based algorithms for RNA secondary structure prediction. BMC Bioinformatics, 13(1), 22.

19. He, Y., Zhu, Y., Chen, J., Huang, M., Wang, G., Zou, W., Wang, P., Zhou, G. 2018. Assessment of land occupation of municipal wastewater treatment plants in China. Environmental Science: Water Research \& Technology, 4(12), 1988-1996.

20. Heinsch, S.C., Hsu, S.-Y., Otto-Hanson, L., Kinkel, L., Smanski, M.J. 2019. Complete genome sequences of Streptomyces spp. isolated from disease-suppressive soils. BMC Genomics, 20(1), 113.

21. Huang, Z., Kong, F., Li, Y., Xu, G., Yuan, R., Wang, S. 2020. Advanced treatment of effluent from municipal wastewater treatment plant by strengthened ecological floating bed. Bioresource Technology, 309, 123358.

22. Johnson, K., van Geest, J., Kleerebezem, R., van Loosdrecht, M.C. 2010. Short-and long-term temperature effects on aerobic polyhydroxybutyrate producing mixed cultures. Water Research, 44(6), 1689-1700.

23. Kalaivani, R., Sukumaran, V. 2013. Isolation and identification of new strains to enhance the production of biopolymers from marine sample in Karankura, Tamil Nadu. European Journal of Experimental Biology, 3(3), 56-64.

24. Khiyami, M.A., Al-Fadual, S.M., Bahklia, A.H. 2011. Polyhydroxyalkanoates production via Bacillus plastic composite support (PCS) biofilm and date palm syrup. Journal of Medicinal Plants Research, 5(14), 3312-3320.

25. Kourmentza, C., Plácido, J., Venetsaneas, N., Burniol-Figols, A., Varrone, C., Gavala, H.N., Reis, M.A. 2017. Recent advances and challenges towards sustainable polyhydroxyalkanoate (PHA) production. Bioengineering, 4(2), 55.

26. Koutník, I., Vráblová, M., Bednárek, J. 2020. Reynoutria japonica, an invasive herb as a source of activated carbon for the removal of xenobiotics from water. Bioresource Technology, 309, 123315.

27. Krishnan, S., Chinnadurai, G.S., Perumal, P. 2017. Polyhydroxybutyrate by Streptomyces sp.: Production and characterization. International Journal of Biological Macromolecules, 104, 11651171. 
28. Kucera, D., Pernicová, I., Kovalcik, A., Koller, M., Mullerova, L., Sedlacek, P., Mravec, F., Nebesarova, J., Kalina, M., Marova, I. 2018. Characterization of the promising poly (3-hydroxybutyrate) producing halophilic bacterium Halomonas halophila. Bioresource Technology, 256, 552-556.

29. Kumar, P., Tripathi, A., Luthra, U., Dubey, K.K. 2020. Enhanced production of lipstatin from mutant of Streptomyces toxytricini and fed-batch strategies under submerged fermentation. 3 Biotech, 10(4), 19.

30. Lai, K.C., Lee, L.Y., Hiew, B.Y.Z., Thangalazhy-Gopakumar, S., Gan, S. 2020. Facile synthesis of xanthan biopolymer integrated 3D hierarchical graphene oxide/titanium dioxide composite for adsorptive lead removal in wastewater. Bioresource Technology, 309, 123296.

31. Linton, E., Rahman, A., Viamajala, S., Sims, R.C., Miller, C.D. 2012. Polyhydroxyalkanoate quantification in organic wastes and pure cultures using a single-step extraction and 1H NMR analysis. Water Science and Technology, 66(5), 1000-1006.

32. López-Cuellar, M., Alba-Flores, J., Rodríguez, J.G., Pérez-Guevara, F. 2011. Production of polyhydroxyalkanoates (PHAs) with canola oil as carbon source. International Journal of Biological Macromolecules, 48(1), 74-80.

33. Macagnan, K.L., Alves, M.I., Rodrigues, A.Á., Furlan, L., da Silva Rodrigues, R., Diaz de Oliveira, P., Vendruscolo, C.T., da Silveira Moreira, A. 2017. Complete factorial design to adjust $\mathrm{pH}$ and sugar concentrations in the inoculum phase of Ralstonia solanacearum to optimize $\mathrm{P}(3 \mathrm{HB})$ production. Plos one, 12(7), e0180563.

34. Mahitha, G., Madhuri, R. 2015. Purification and characterization of polyhydroxybutyrate produced from marine bacteria. International Journal of Science and Engineering Research, 6, 71-75.

35. Maskow, T., Babel, W. 2000. Calorimetrically recognized maximum yield of poly-3-hydroxybutyrate (PHB) continuously synthesized from toxic substrates. Journal of Biotechnology, 77(2-3), 247-253.

36. Mohapatra, S., Mohanta, P., Sarkar, B., Daware, A., Kumar, C., Samantaray, D. 2017. Production of polyhydroxyalkanoates (PHAs) by Bacillus strain isolated from waste water and its biochemical characterization. Proceedings of the National Academy of Sciences, India Section B: Biological Sciences, 87(2), 459-466.

37. Moradali, M.F., Rehm, B.H. 2020. Bacterial biopolymers: from pathogenesis to advanced materials. Nature Reviews Microbiology, 1-16.

38. Mostafa, Y.S., Alrumman, S.A., Otaif, K.A., Alamri, S.A., Mostafa, M.S., Sahlabji, T. 2020. Production and Characterization of Bioplastic by Polyhydroxybutyrate Accumulating Erythrobacter aquimaris Isolated from Mangrove Rhizosphere. Molecules, 25(1), 179.

39. Narayanan, A., Ramana, K.V. 2012. Polyhydroxybutyrate production in Bacillus mycoides DFC1 using response surface optimization for physico-chemical process parameters. 3 Biotech, 2(4), 287-296.

40. Narayanan, M., Kandasamy, S., Kumarasamy, S., Gnanavel, K., Ranganathan, M., Kandasamy, G. 2020. Screening of polyhydroxybutyrate producing indigenous bacteria from polluted lake soil. Heliyon, 6(10), e05381. 
41. Ni, Y.-Y., Chung, M.G., Lee, S.H., Park, H.-Y., Rhee, Y.H. 2010. Biosynthesis of medium-chain-length poly (3-hydroxyalkanoates) by volatile aromatic hydrocarbons-degrading Pseudomonas fulva TY16. Bioresource Technology, 101(21), 8485-8488.

42. Niether, W., Glawe, A., Pfohl, K., Adamtey, N., Schneider, M., Karlovsky, P., Pawelzik, E. 2020. The effect of short-term vs. long-term soil moisture stress on the physiological response of three cocoa (Theobroma cacao L.) cultivars. Plant Growth Regulation, 92(2), 295-306.

43. Nwinyi, O.C., Owolabi, T.A. 2019. Scanning electron microscopy and Fourier transmission analysis of polyhydroxyalkanoates isolated from bacteria species from abattoir in Ota, Nigeria. Journal of King Saud University-Science, 31(3), 285-298.

44. Patel, N., Patel, P., Desai, R. 2017. Detection \& characterization of PHB (polyhydroxybutyrate) Producers halophilic bacteria isolated from marine water sample of Valsad District. International Journal of Pharma and Bio Science, 8, 1100.

45. Pérez, V., Mota, C.R., Muñoz, R., Lebrero, R. 2020. Polyhydroxyalkanoates (PHA) production from biogas in waste treatment facilities: Assessing the potential impacts on economy, environment and society. Chemosphere, 126929.

46. Rendón-Villalobos, R., Ortíz-Sánchez, A., Tovar-Sánchez, E., Flores-Huicochea, E. 2016. The Role of Biopolymers in Obtaining Environmentally Friendly Materials. Composites from Renewable and Sustainable Materials, 151.

47. Sabarinathan, D., Chandrika, S.P., Venkatraman, P., Easwaran, M., Sureka, C.S., Preethi, K. 2018. Production of polyhydroxybutyrate (PHB) from Pseudomonas plecoglossicida and its application towards cancer detection. Informatics in Medicine Unlocked, 11, 61-67.

48. Salgaonkar, B.B., Bragança, J.M. 2017. Utilization of sugarcane bagasse by Halogeometricum borinquense strain E3 for biosynthesis of poly (3-hydroxybutyrate-co-3-hydroxyvalerate). Bioengineering, 4(2), 50.

49. Sasidharan, R.S., Bhat, S.G., Chandrasekaran, M. 2015. Biocompatible polyhydroxybutyrate (PHB) production by marine Vibrio azureus BTKB33 under submerged fermentation. Annals of Microbiology, 65(1), 455-465.

50. Sathiyanarayanan, G., Saibaba, G., Kiran, G.S., Selvin, J. 2013. A statistical approach for optimization of polyhydroxybutyrate production by marine Bacillus subtilis MSBN17. International Journal of Biological Macromolecules, 59, 170-177.

51. Shanmugam, M., Abirami, R. 2019. Microbial polysaccharides-chemistry and applications. Journal of Biologically Active Products from Nature, 9(1), 73-78.

52. Singh, G., Mittal, A., Kumari, A., Goel, V., Aggarwal, N.K., Yadav, A. 2011. Optimization of poly-Bhydroxybutyrate production from Bacillus species. European Journal of Biological Sciences, 3(4), 112-116.

53. Singh Saharan, B., Grewal, A., Kumar, P. 2014. Biotechnological production of polyhydroxyalkanoates: a review on trends and latest developments. Chinese Journal of Biology, 2014. 
54. Soam, A., Singh, A., Singh, R., Shahi, S. 2012. Optimization of culture conditions for bio-polymer producing Bacillus mycoides (WSS2) bacteria from sewage. Current Discovery, 1, 27-32.

55. Tajima, K., Igari, T., Nishimura, D., Nakamura, M., Satoh, Y., Munekata, M. 2003. Isolation and characterization ofbacillus sp. Int005 accumulating polyhydroxyalkanoate (PHA) from gas field soil. Journal of Bioscience and Bioengineering, 95(1), 77-81.

56. Umesh, M., Priyanka, K., Thazeem, B., Preethi, K. 2018. Biogenic PHA nanoparticle synthesis and characterization from Bacillus subtilis NCDC0671 using orange peel medium. International Journal of Polymeric Materials and Polymeric Biomaterials, 67(17), 996-1004.

57. Valappil, S.P., Rai, R., Bucke, C., Roy, I. 2008. Polyhydroxyalkanoate biosynthesis in Bacillus cereus SPV under varied limiting conditions and an insight into the biosynthetic genes involved. Journal of Applied Microbiology, 104(6), 1624-1635.

58. Villano, M., Beccari, M., Dionisi, D., Lampis, S., Miccheli, A., Vallini, G., Majone, M. 2010. Effect of pH on the production of bacterial polyhydroxyalkanoates by mixed cultures enriched under periodic feeding. Process Biochemistry, 45(5), 714-723.

59. Xiong, J.-Q., Ru, S., Zhang, Q., Jang, M., Kurade, M.B., Kim, S.-H., Jeon, B.-H. 2020. Insights into the effect of cerium oxide nanoparticle on microalgal degradation of sulfonamides. Bioresource Technology, 309, 123452.

60. Yalpani, M., Marchessault, R.H., Morin, F.G., Monasterios, C.J. 1991. Synthesis of poly (3hydroxyalkanoate)(PHA) conjugates: PHA-carbohydrate and PHA-synthetic polymer conjugates. Macromolecules, 24(22), 6046-6049.

61. Zhang, Q., Gao, X., Jin, Y., Zhao, L., Zhu, H., Zhang, P. 2020. Modified steel slag for effect prolongation of calcium peroxide: A novel approach to enhancing SCFAs production from sludge anaerobic fermentation. Bioresource Technology, 309, 123379.

62. Zikmanis, P., Kolesovs, S., Semjonovs, P. 2020. Production of biodegradable microbial polymers from whey. Bioresources and Bioprocessing, 7(1), 1-15.

\section{Figures}

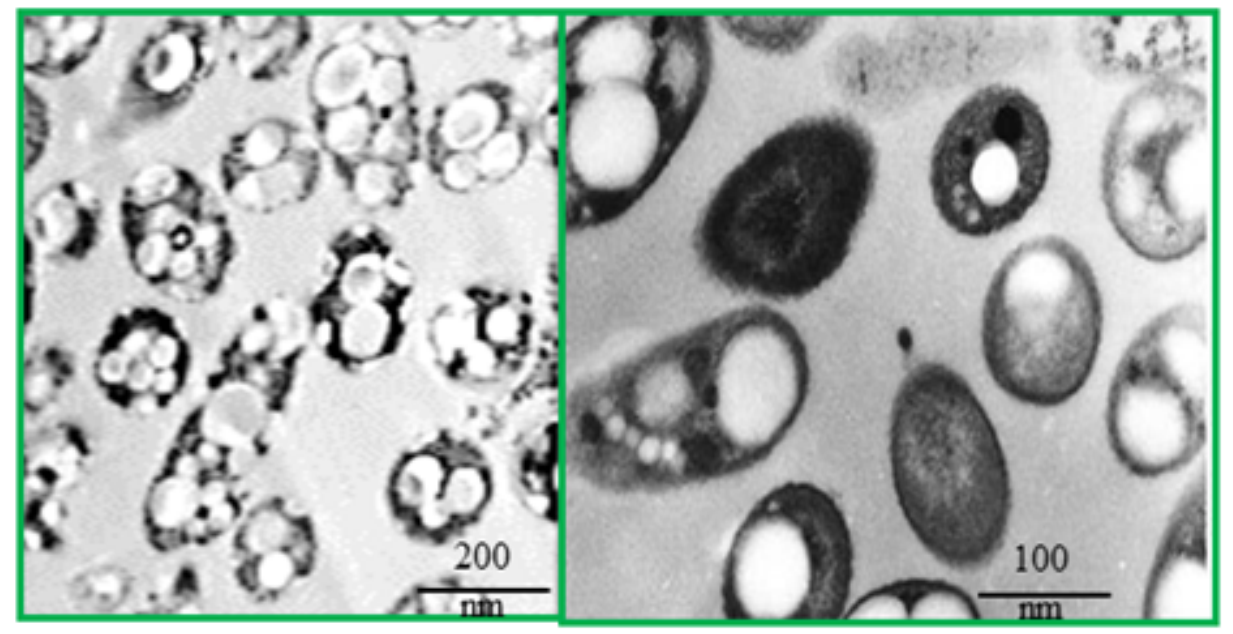


Figure 1

TEM analysis with various magnifications. Ovoid with elongated shape PHAs granules observed in test isolate $\mathrm{HO9}$

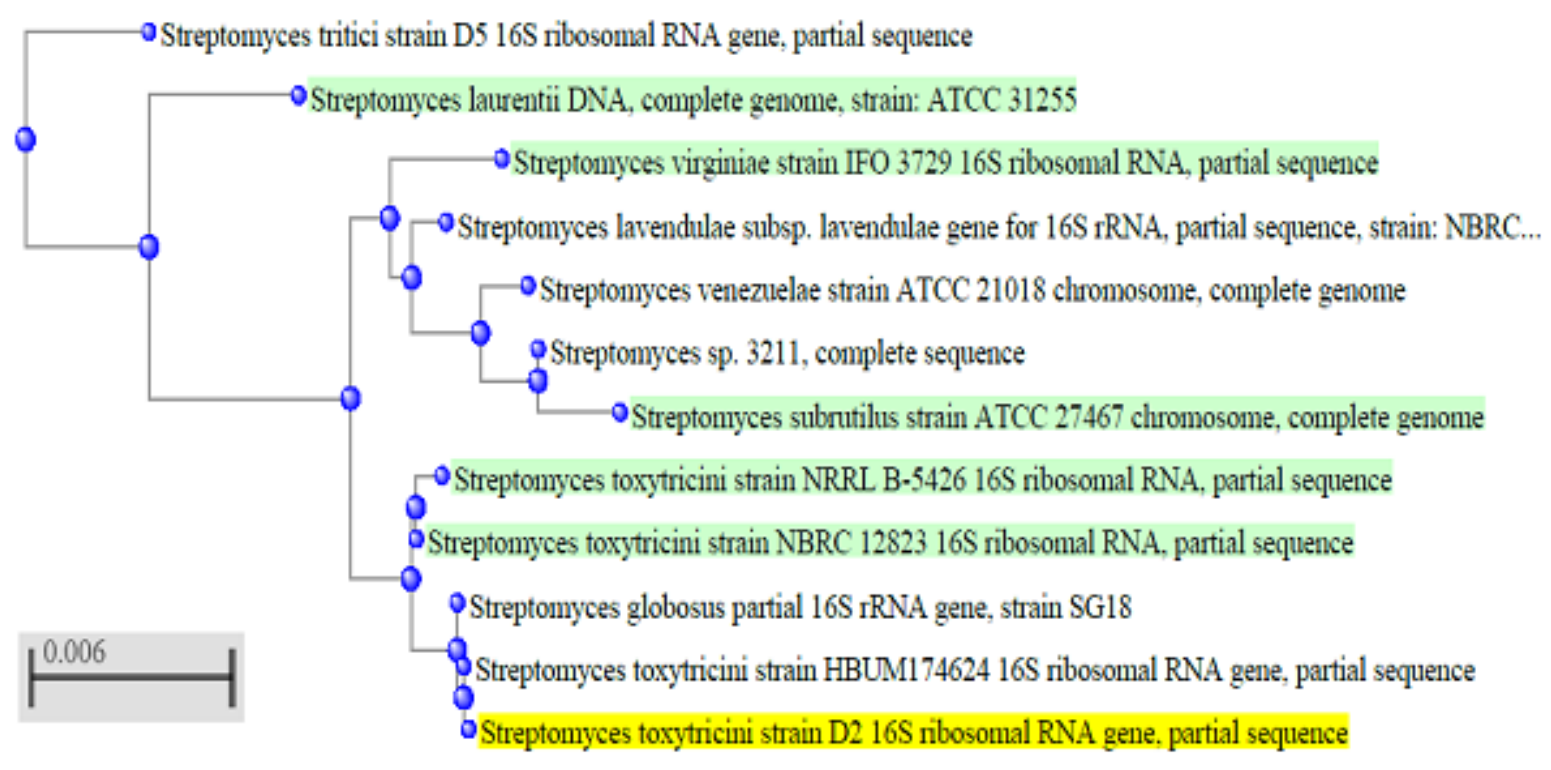

Figure 2

Phylogenetic analysis of 16S rRNA sequence of S. toxytricini D2 


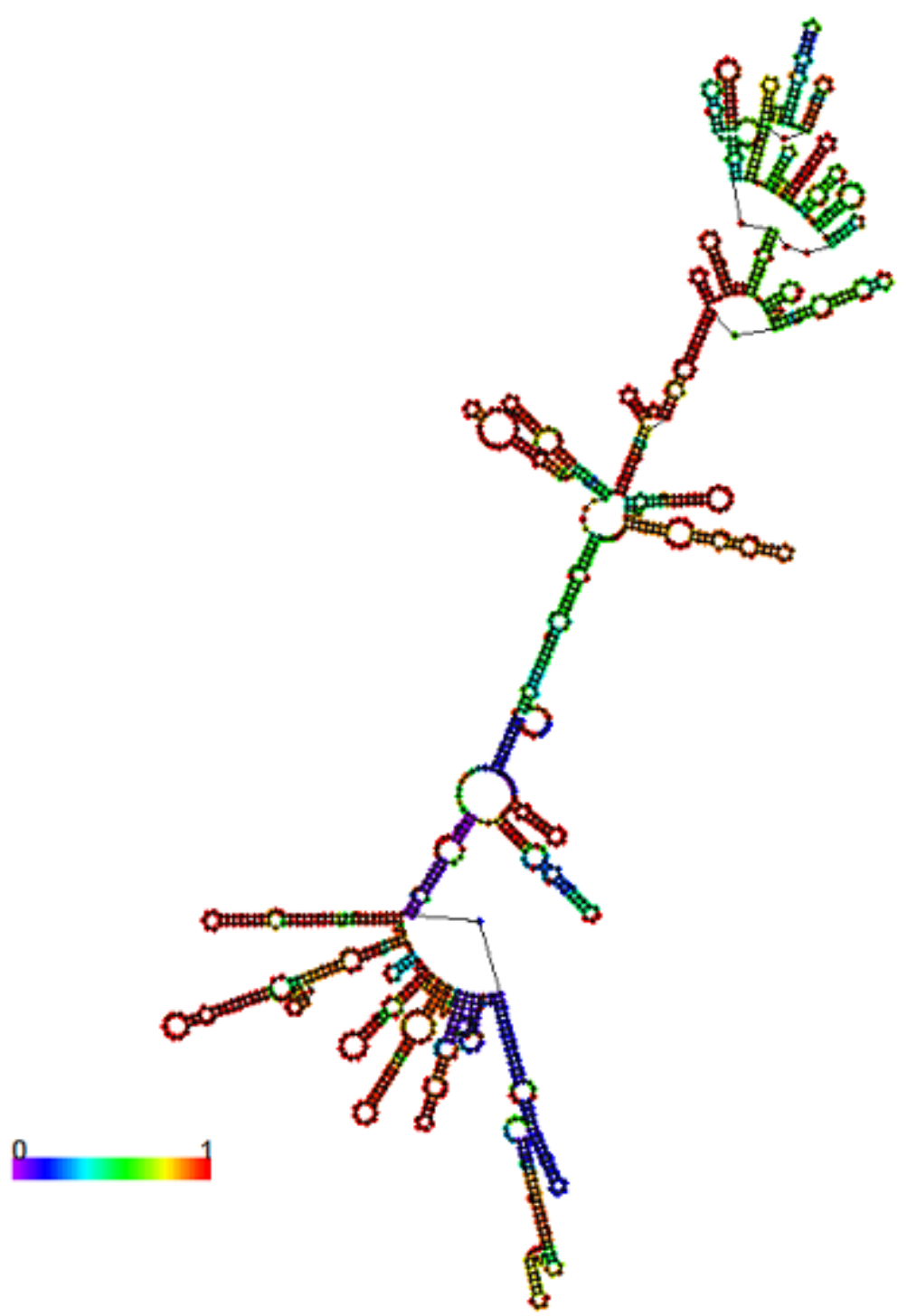

Figure 3

MFE secondary structure of S. toxytricini D2 
NEBcutter

Display: - NEB single cutter restriction enzymes - Main non-overlapping, min. 100 aa ORFs

$\mathrm{GC}=58 \%, \mathrm{AT}=42 \%$

\begin{tabular}{|c|l|}
\hline Cleavage code & Enzyme name code \\
I blunt end cut & Available from NEB \\
Has other supplier \\
I 5' extension & Not commercially available \\
- I 3' extension & *: cleavage affected by CpG methylation \\
\#: cleavage affected by other methylation \\
(enz. name): ambiguous site
\end{tabular}

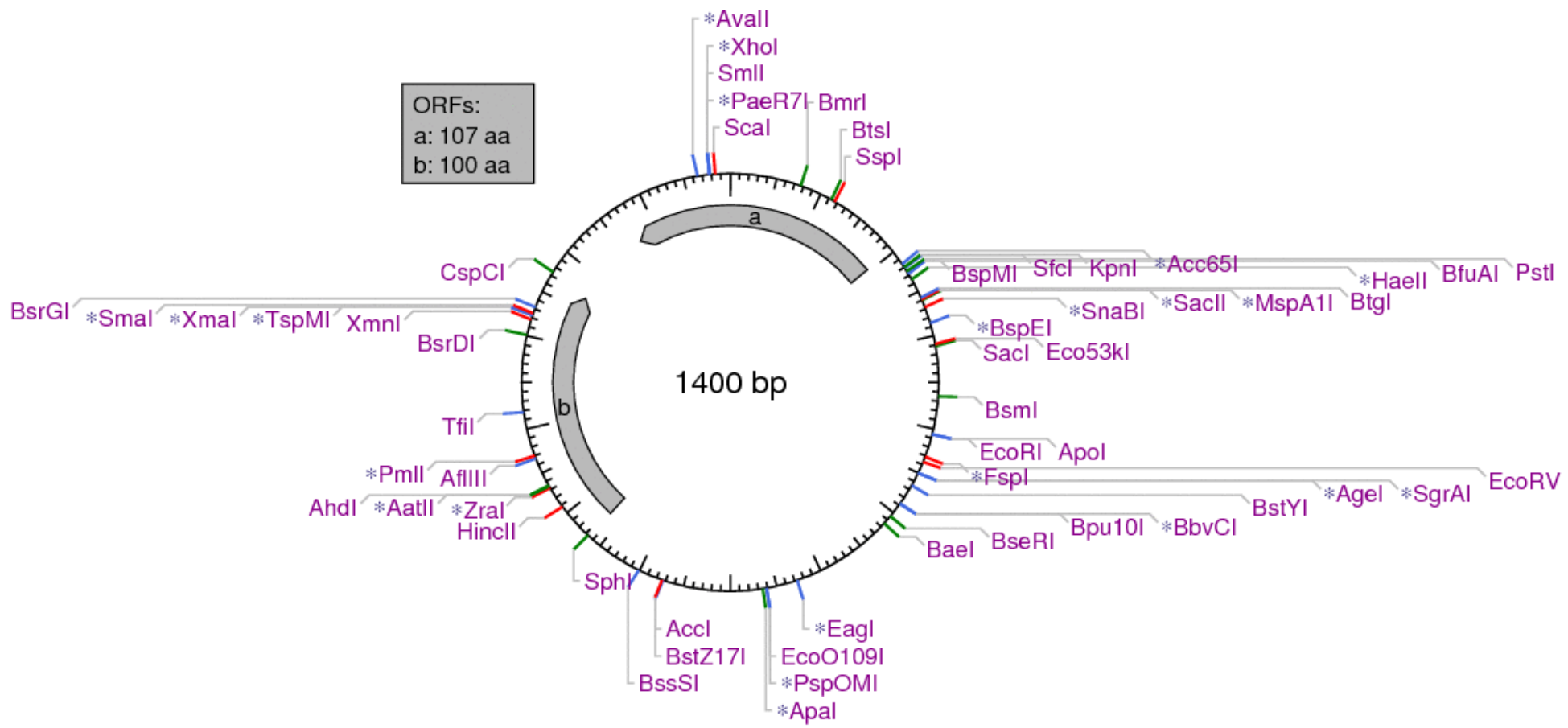

\section{Figure 4}

Circular sequence structure with possible restriction sites positions of S. toxytricini D2 


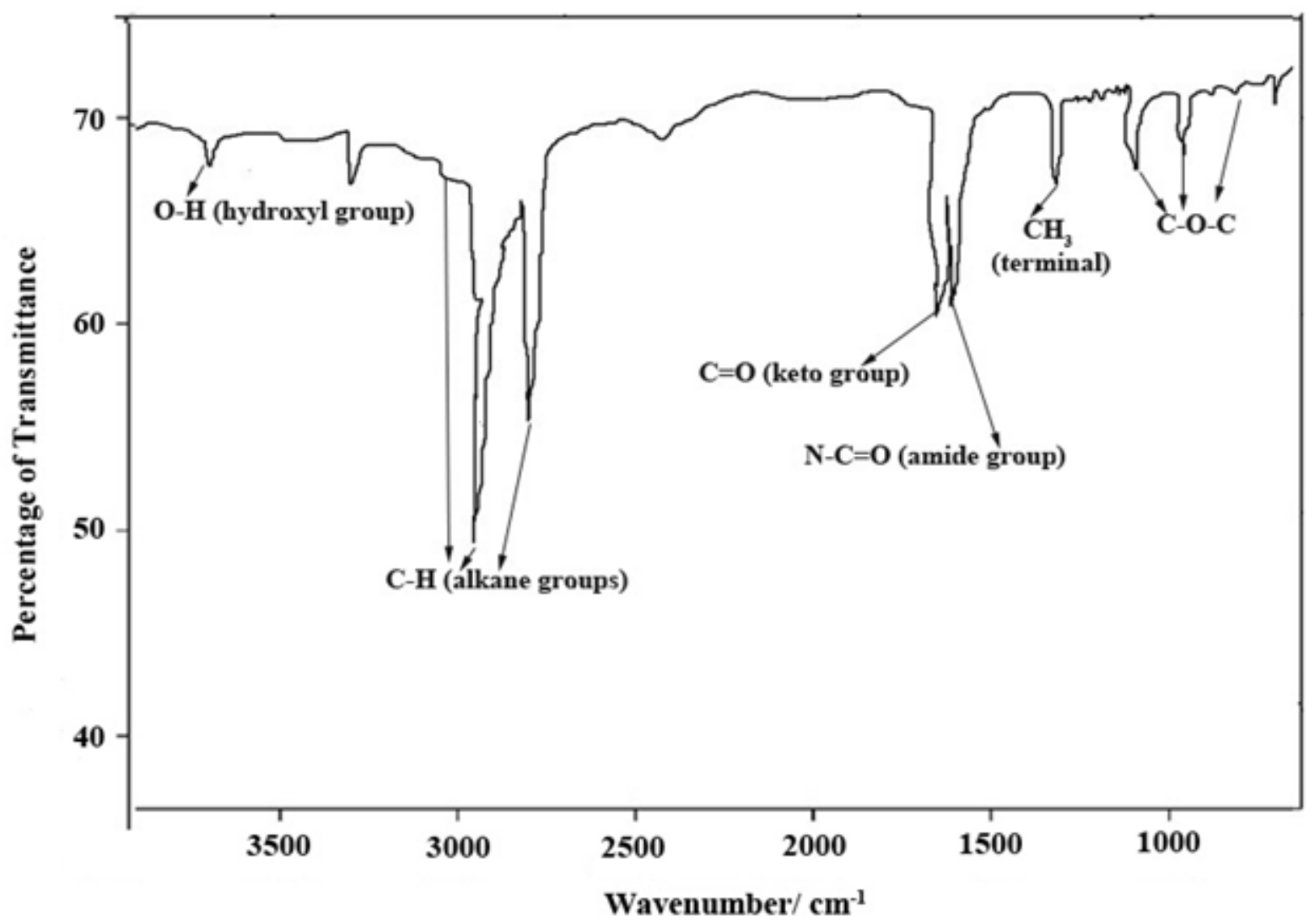

Figure 5

FTIR analysis of PHAs extracted from S. toxytricini D2

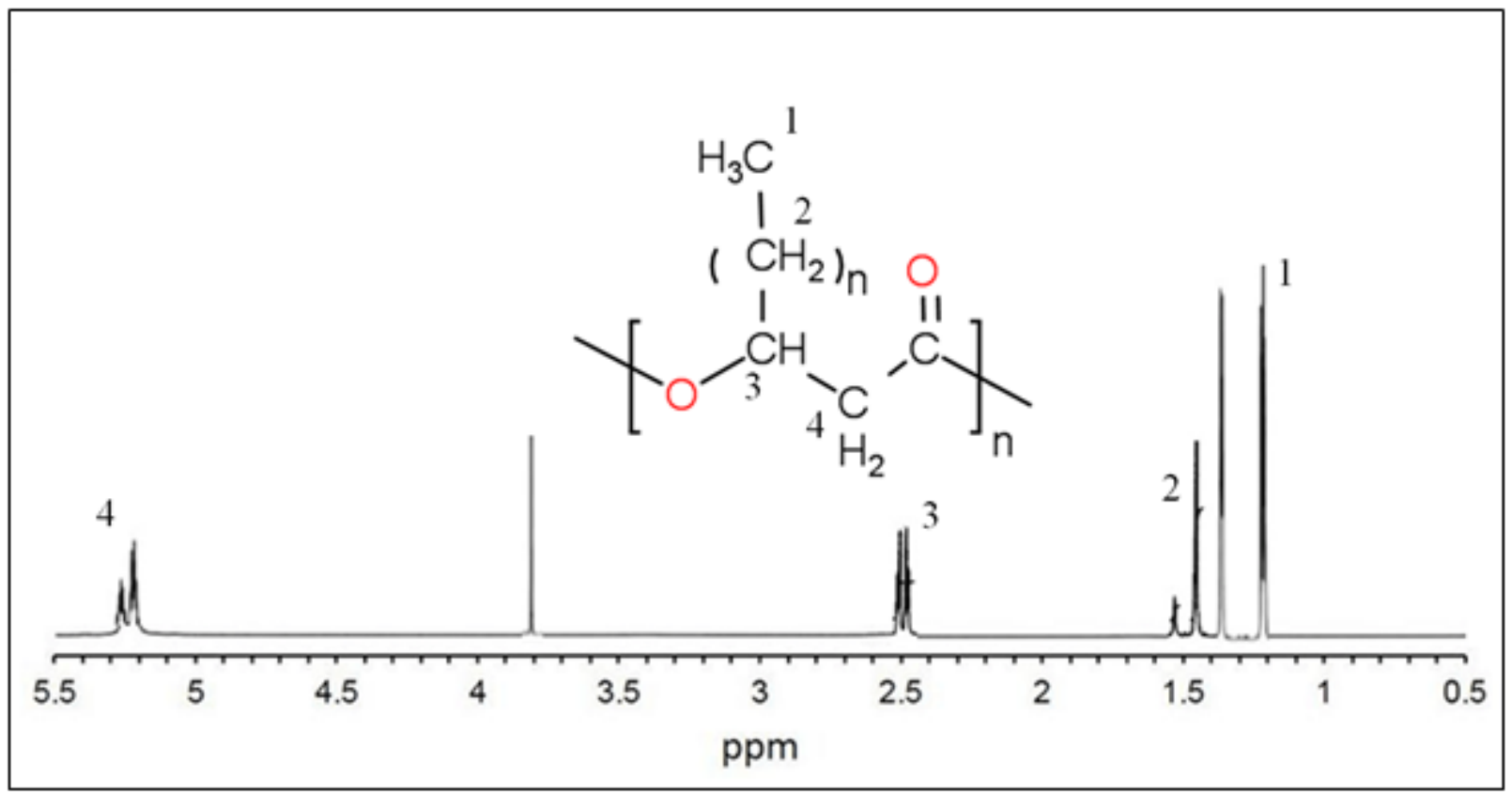

Figure 6 
1H NMR analysis of PHAs extracted from S. toxytricini D2

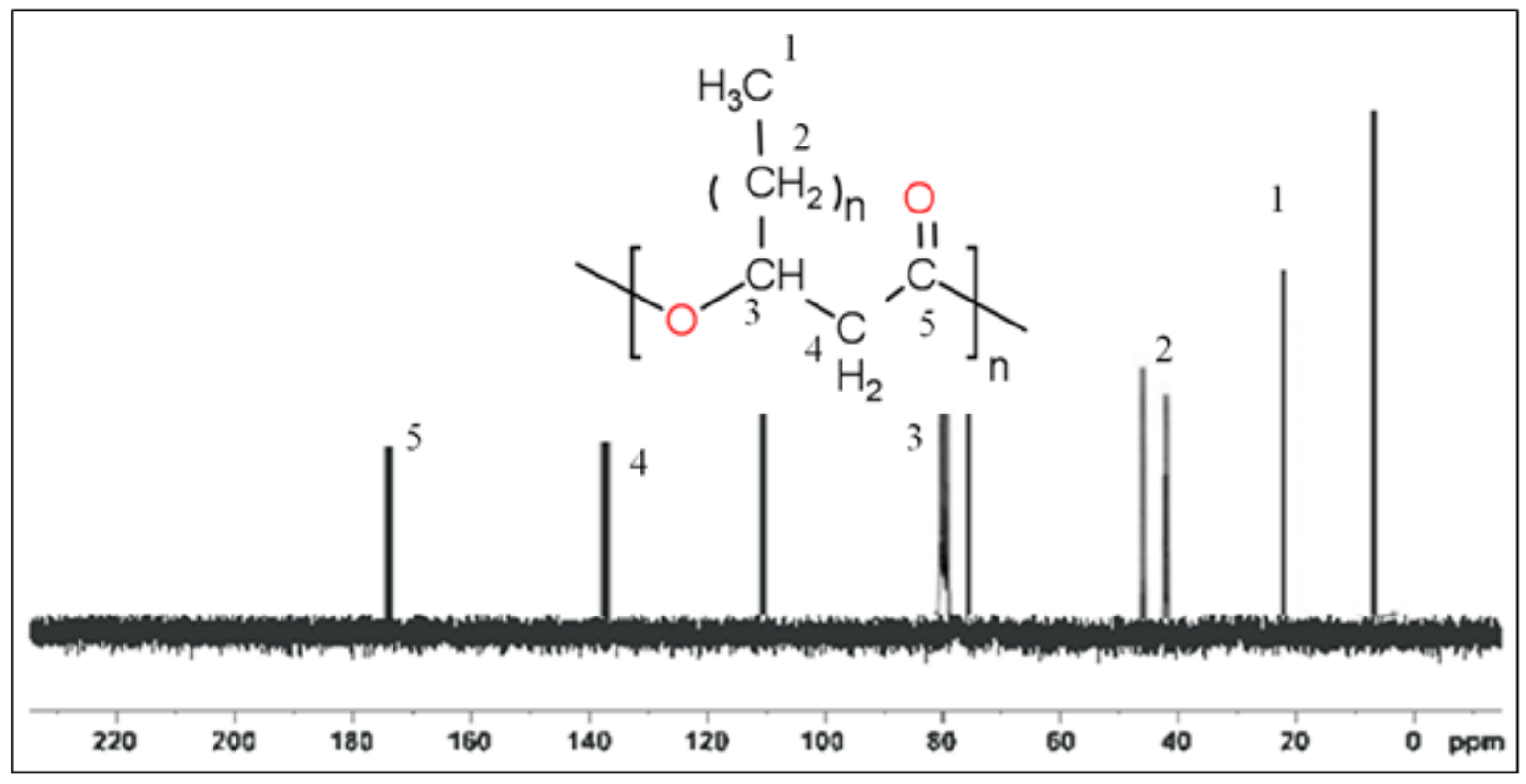

Figure 7

13C NMR analysis of PHAs extracted from S. toxytricini D2 

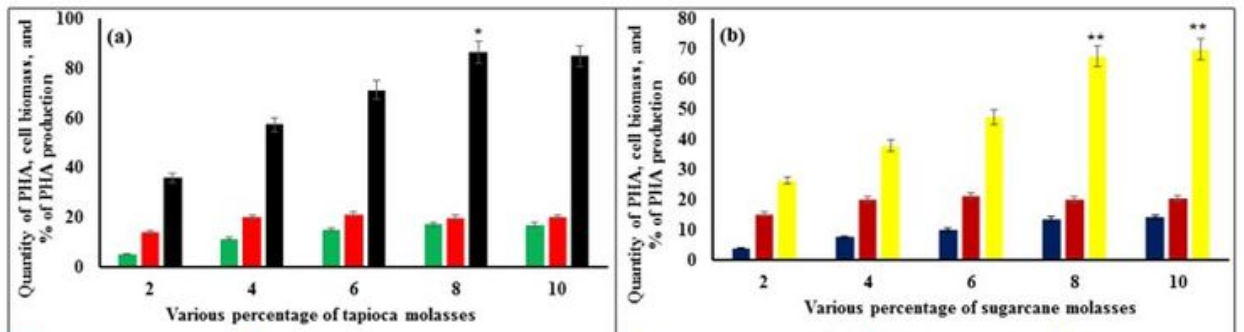

= PHA production $\left(\mathrm{g} \mathrm{L}^{-1}\right) \quad$ Cell biomass $\left(\mathrm{g} \mathrm{L}^{-1}\right)$ - PHA production $(\%) \quad$ - PHA production $\left(\mathrm{gL}^{-1}\right) \quad=$ Cell biomass $\left(\mathrm{g} \mathrm{L}^{-1}\right)$ PHA production $(\%)$
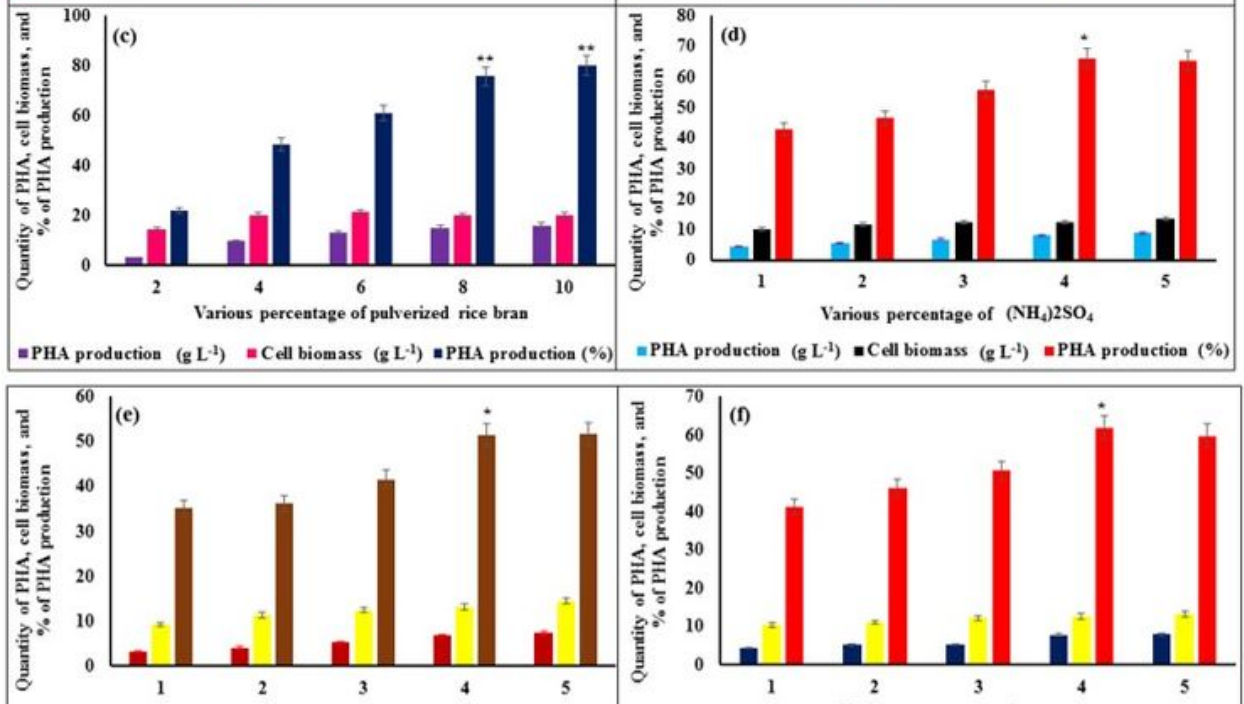

- $\mathrm{PHA}$ production $\left(\mathrm{g} \mathrm{L}^{-1}\right) \quad$ Cell biomass $\left(\mathrm{g} \mathrm{L}^{-1}\right)$ m $\mathrm{PHA}$ production (\%)

- PHA production $\left(\mathrm{g} \mathrm{L}^{-1}\right) \quad$ Cell biomass $\left(\mathrm{g} \mathrm{L}^{-1}\right)$ a PHA production $(\%)$
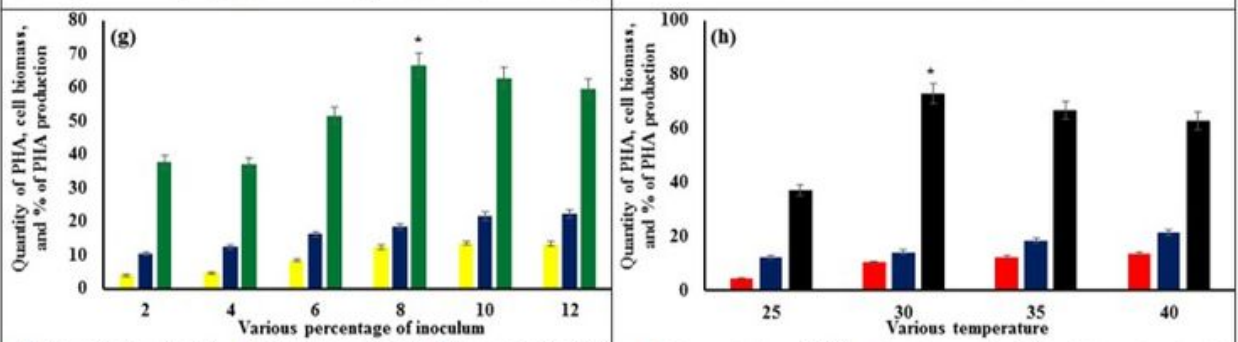

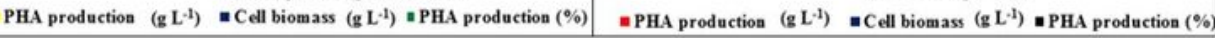

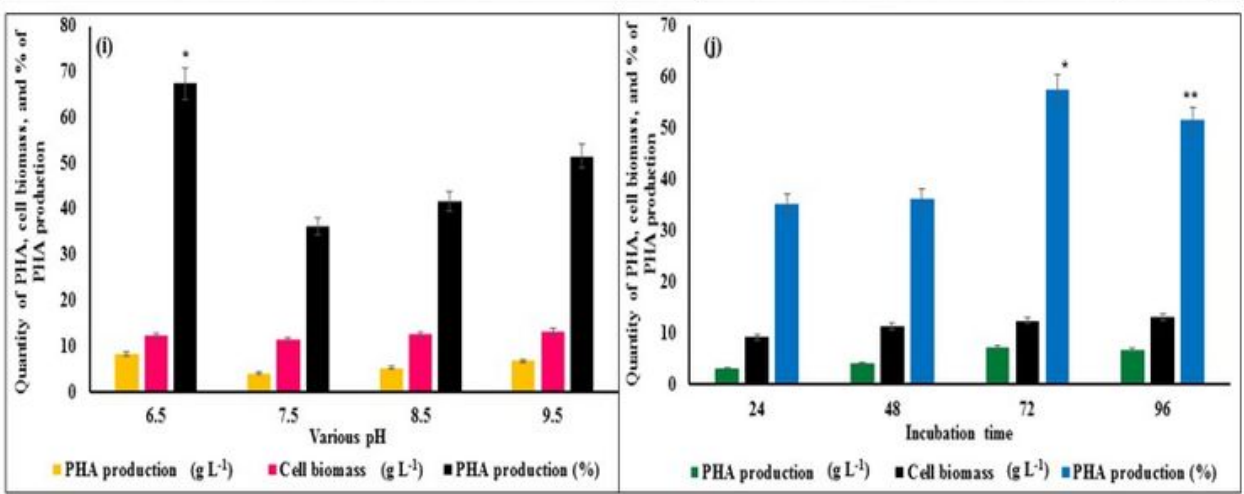

Figure 8

Growth parameters optimization for PHAs fabrication by S. toxytricini D2 


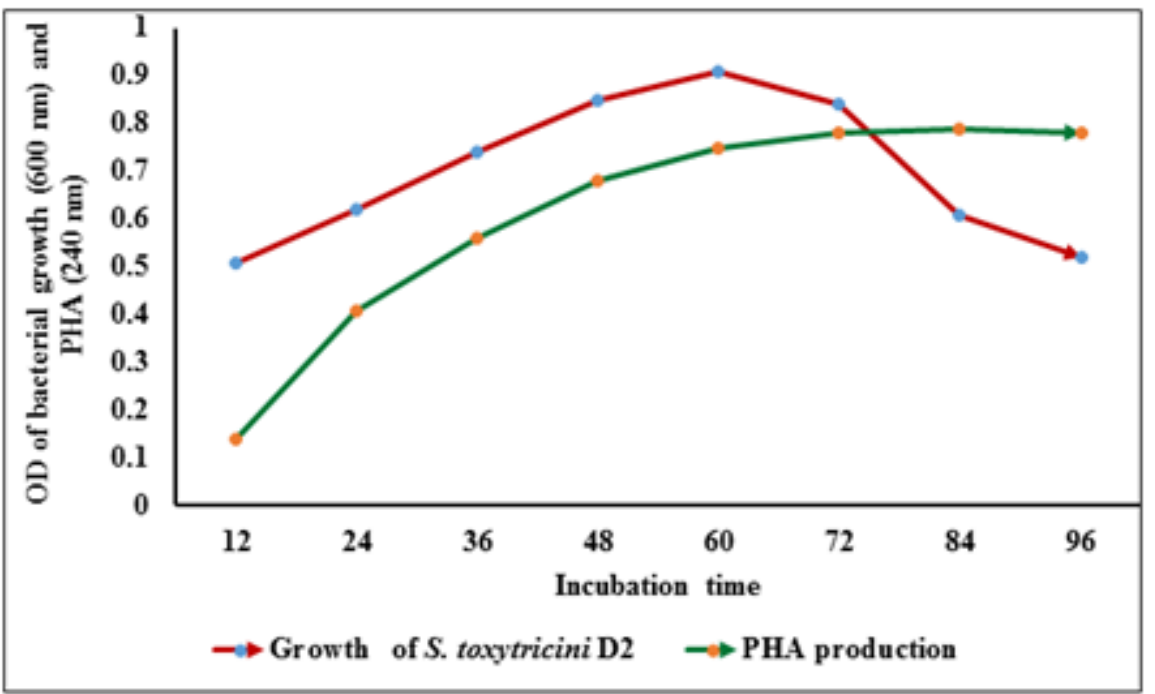

Figure 9

Growth kinetics and PHAs production under optimized growth conditions 